\title{
Primary Use of Negative Pressure Dressings in Lower Extremity Distal Bypass Wounds
}

\author{
Anantha K Ramanathan ${ }^{1 *}$ and George Papas ${ }^{2}$ \\ ${ }^{1}$ Surgical Angiology Institute, 28C, 654, Pacific Highway, Kanwal, NSW 2259, Australia \\ ${ }^{2}$ Wyong Hospital, Wyong, NSW 2259, Australia
}

\begin{abstract}
Introduction: Wound complications of leg wounds occur in up to $44 \%$ of patients after femoral distal bypass surgery. There are technical difficulties in obtaining primary wound closure especially on the anterior tibial wound, particularly in the setting of critical limb ischaemia and oedema.

Technical summary: Primary use of negative pressure dressings in this situation has not been described. We describe a case report and a technique which will help obtain safe wound closure without compromising graft integrity by tunnelling the graft obliquely under the tibialis anterior muscle and then applying primary Pico ${ }^{\mathrm{TM}}$ dressing.

Conclusion: By avoiding tension on fragile oedematous tissue safe wound closure may be obtained.

Consent: Informed patient consent was obtained for the treatment as well as for the publication of the photograph.
\end{abstract}

Keywords: Femoral distal bypass; Wound complications; Primary vacuum assisted closure

\section{Introduction}

Wound complications are common and occur in $17-44 \%$ of patients after infra inguinal bypasses [1]. Many of these occur in the lower end of the wound [2], and can compromise graft integrity [3]. Wound complications may start a cascade of events that result in prolonged hospital stay, amputations and even death. Bypasses to the anterior tibial and dorsalis pedis arteries are particularly at risk.

Chronic critical limb ischemia is associated with substantial oedema of the affected limb [4]. A major portion of this is in the subcutaneous tissue but the oedema also affects the muscles [5]. Once deep fascia is incised and the muscle is released from its compartment, it tends to bulge. This makes wound approximation challenging. Avoiding tension in wound closure is important.

In our experience the anterior tibial wound is most at risk for inability to close due to tension. Our goal was to see if the use of negative pressure dressing directly over the wound that is left open will help to overcome this problem.

\section{Case Report}

A 66 year old man presented to us with rest pain of the left foot of one month duration. The patient had severe left sided weakness from a previous embolic stroke from the right internal carotid artery origin. Though he was mostly wheelchair bound he used the left leg for transfer and walking inside the house. The patient was a type 2 diabetic on oral medication. He also had hypertension and hypercholesterolemia. He did not have ischaemic heart disease. There was a past history of left sided deep vein thrombosis. He was an ex-smoker.

Examination revealed an obese patient. He was on a wheelchair but was able to transfer. He was in sinus rhythm. There was no bruit over the carotids. There was no bruit over the precordium. Examination of the abdomen was unremarkable except for a para umbilical hernia. The femoral pulses were palpable on both sides. On the left side the popliteal or the foot pulses could not be palpated. The left lower extremity was swollen and discoloured and the capillary refill was sluggish. The ankle brachial pressure index (ABPI) was .23. The right lower extremity was normal with palpable pulses and an ABPI of .97.

Duplex scan revealed patent vessels down to the common femoral artery, occlusion of the left superficial femoral artery from its origin and a short isolated popliteal segment which re-occluded. The tibio peroneal trunk, peroneal and posterior tibial arteries were occluded. There was a single vessel runoff which was the anterior tibial artery. The origin of the anterior tibial was occluded. The rest of the vessel was patent to the foot.

Attempts at endovascular revascularization failed. The great saphenous vein was not suitable. Therefore the patient underwent a left femoral to anterior tibial bypass with a heparin bonded PTFE graft using Miller cuff.

Because of the swelling of the muscle and subcutaneous tissue, primary skin closure was not possible. Therefore the technique mentioned below was used. This proved to be successful and the wound healed up well and the graft has been patent 18 months later. The symptoms have resolved.

The technique has since been used successfully by us on other patients too.

\section{Technique}

Negative pressure therapy using $\mathrm{PICO}^{\mathrm{TM}}$ dressing is applied primarily on the open anterior tibial surgical wound where there is

*Corresponding author: A. Ramanathan, 1Surgical Angiology Institute, 28C, 654 Pacific Highway, Kanwal, NSW 2259, Australia, E-mail: aram02@gmail.com

Received September 30, 2015; Accepted October 23, 2015; Published October 30, 2015

Citation: Ramanathan AK, Papas G (2015) Primary Use of Negative Pressure Dressings in Lower Extremity Distal Bypass Wounds. J Cardiovasc Dis Diagn 3: 228. doi:10.4172/2329-9517.1000228

Copyright: () 2015 Ramanathan AK, et al. This is an open-access article distributed under the terms of the Creative Commons Attribution License, which permits unrestricted use, distribution, and reproduction in any medium, provided the original author and source are credited. 


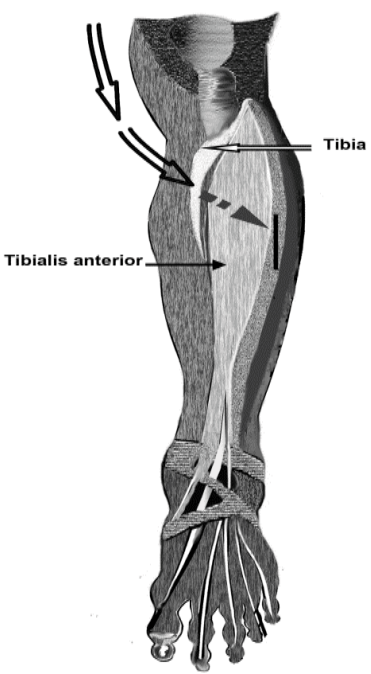

Figure 1: shows the oblique course of the tunnel under the tibialis anterior to reach the surgical incision.

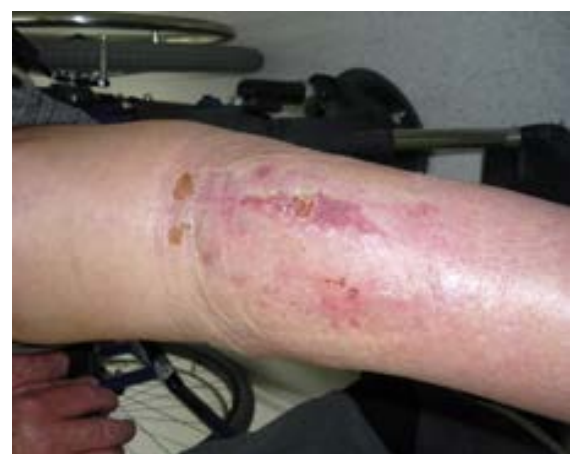

Figure 2: Shows a healed wound after use of this technique.

excess swelling. At completion of surgery the wound is left open and the PICO dressing is applied and negative pressure of $-70 \mathrm{~mm} \mathrm{Hg}$ is started immediately. The bulging tibialis anterior muscle which causes skin tension becomes an ally if the tunnelling is done to have the graft run obliquely deep to the muscle once it crosses the edge of the tibia (Figure 1). The muscle then overlies the graft and the negative pressure dressing can be applied directly over it.

All wounds closed in this way have healed and have remained healed (follow up of up to 18 months) (Figure 2).

\section{Discussion}

Various strategies have been used to overcome the problem of skin closure after distal bypasses in swollen limbs. Relaxing incisions with primary skin grafting have been used. Use of negative pressure therapy in vascular surgery is well documented. Negative pressure dressings on exposed infected grafts [6,7] and on wounds after skin closure [8] , have been described. Primary use of negative pressure dressings on open anterior tibial surgical wounds has not been described. By tunnelling obliquely under the tibialis anterior the muscle can be used to protect the graft from being exposed to the outside and to minimises the risk of suction injury to the graft, and to avoid exposure of the graft with risk of graft infection.

\section{References}

1. Schwartz ME, Harrington EB, Schanzer H (1988) Wound complications after in situ bypass. J Vasc Surg 7: 802-807.

2. Reifsnyder T, Bandyk D, Seabrook G (1992) Wound complications of the in situ saphenous vein bypass technique. J Vasc Surg 15: 843-850.

3. Wengrovitz M, Atnip RG, Gifford RRM (1990) Wound complications of autogenous subcutaneous infrainguinal arterial bypass surgery: Predisposing factors and management. J Vasc Surg 11: 156-163.

4. Khiabani HZ, Anvar MD, Stranden E (1999) Oedema in the lower limb of patients with chronic critical limb ischaemia (CLI). Eur J Vasc Endovasc Surg 17: 419-423.

5. Khiabani HZ, Anvar MD, Rostad B (1999) The distribution of oedema in the lower limb of patients with chronic critical limb ischaemia: a study with computed tomography. VASA 28: 265-270.

6. Dosluoglu HH, Schimpf DK, Schultz R, Cherr GS (2005) Preservation of infected and exposed vascular grafts using vacuum assisted closure without muscle flap coverage. J Vasc Surg 42: 989-992.

7. Berger P, de Bie D, Moll FL, de Borst GJ (2012) Negative pressure wound therapy on exposed prosthetic vascular grafts in the groin. J Vasc Surg 56 714-720.

8. Haghshenasskashani A, Varcoe RL (2011) A new negative pressure dressing (Prevena) to prevent wound complications following lower limb distal arteria bypass. Br J Diabetes Vasc Dis 11: 21-24. 